\title{
Desengajamento moral e o bullying em contexto escolar
}

\author{
Moral disengagement and bullying in school context \\ Desarrollo moral y el bullying en contexto escolar
}

Recebido: 05/01/2021 | Revisado: 12/01/2021 | Aceito: 19/01/2021 | Publicado: 24/01/2021

\author{
Ariane Lilian Lima dos Santos Melo Rodrigues \\ ORCID: https://orcid.org/0000-0002-1221-1863 \\ Universidade Federal do Pará, Brasil \\ arianemelo.adv@gmail.com \\ Maély Ferreira Holanda Ramos \\ ORCID: https://orcid.org/0000-0001-6150-6345 \\ Universidade Federal do Pará, Brasil \\ maelyramos@hotmail.com \\ Emmanuelle Pantoja Silva \\ ORCID: https://orcid.org/0000-0003-0134-4350 \\ Universidade Federal do Pará, Brasil \\ emmanuellepantojas@gmail.com
}

\begin{abstract}
Resumo
Objetiva-se verificar se estudantes com idade entre 11 e 18 anos tiveram algum envolvimento em situações de violência (bullying) e avaliar a existência de uma tendência a justificarem atos de agressividade, por meio dos mecanismos do desengajamento moral. Para tanto se realizou um estudo com 430 alunos de duas escolas públicas em Belém - PA. Utilizaram-se dois instrumentos, um para caracterizar a amostra e averiguar situações de bullying; e o outro, para analisar os mecanismos do construto. Dos principais resultados obtidos, observou-se que mais de $37 \%$ da amostra já se envolveu em situações de bullying e 46\% referiu que não se sentia seguro no ambiente escolar. Por outro lado, percebeu-se que em todos os mecanismos houve tendência dos alunos justificarem atos agressivos. Diante dos resultados, conclui-se que a prática do bullying é uma realidade nas escolas estudadas e que existe uma tendência dos alunos justificarem condutas agressivas.
\end{abstract}

Palavras-chave: Alunos; Bullying; Desengajamento moral; Teoria social cognitiva.

\begin{abstract}
The objective was to verify if students aged between 11 and 18 years had any involvement in situations of violence (bullying) and to evaluate the existence of a tendency to justify acts of aggression, through the mechanisms of moral disengagement. For that, a study was carried out with 430 students from two public schools in Belém - PA. Two instruments were used, one to characterize the sample and to investigate situations of bullying; and the other to analyze the mechanisms of the construct. Of the main results obtained, it was observed that more than $37 \%$ of the sample was already involved in bullying situations and 46\% reported that they did not feel safe in the school environment. On the other hand, it was noticed that in all the mechanisms there was tendency of the students to justify aggressive acts. Given the results, it is concluded that the practice of bullying is a reality in the schools studied and that there is a tendency of students to justify aggressive behavior.
\end{abstract}

Keywords: Students; Bullying; Moral disengagement; Cognitive social theory.

\section{Resumen}

Se pretende verificar si los estudiantes con edad entre 11 y 18 años tuvieron algún involucramiento en situaciones de violencia (bullying) y evaluar la existencia de una tendencia a justificar actos de agresividad, por medio de los mecanismos del desarrollo moral. Para ello se realizó un estudio con 430 alumnos de dos escuelas públicas en Belém PA. Se utilizaron dos instrumentos, uno para caracterizar la muestra y averiguar situaciones de bullying; y el otro, para analizar los mecanismos del constructo. De los principales resultados obtenidos, se observó que más del $37 \%$ de la muestra ya se involucró en situaciones de bullying y el $46 \%$ refirió que no se sentía seguro en el ambiente escolar. Por otro lado, se percibió que en todos los mecanismos hubo tendencia de los alumnos justificar actos agresivos. Ante los resultados, se concluye que la práctica del bullying es una realidad en las escuelas estudiadas y que existe una tendencia de los alumnos a justificar conductas agresivas.

Palabras clave: Alumnos; Intimidación; Desarrollo moral; Teoría social cognitiva. 


\section{Introdução}

A violência está presente constantemente na história das civilizações, identificada como fruto das relações sociais, sendo alvo contumaz da Organização Mundial da Saúde - OMS, principalmente quando ocorre nos ambientes em que a presença de crianças e adolescentes seja constante, como no seio familiar e dentro das escolas (Matos, Martins, Jesus \& Viseu, 2015). Dentre os tipos de violência ocorridos no ambiente escolar, destaca-se o bullying como uma modalidade antiga, que vem evoluindo e atraindo interesse de estudiosos, por ser considerado um problema que afeta jovens do mundo inteiro (Olweus, 1995). No Brasil, os estudos científicos sobre o fenômeno do bullying ainda são incipientes e concentram-se mais na região sul e sudeste do país, sendo necessário estudar o fenômeno de forma regionalizada, no nordeste e norte do país, para realizar um diagnóstico mais próximo da realidade (Silva \& Costa, 2017).

A Lei 13.185/2016 denomina o bullying como intimidação sistemática, que, segundo a legislação, é todo tipo de violência praticada por uma ou mais pessoas, contra um grupo ou um único indivíduo, de maneira repetitiva e intencional, sem motivos específicos, mas com uma relação de desequilíbrio de poder entre as partes envolvidas na demanda (Brasil, 2015). O bullying pode ocorrer de maneira presencial ou virtualmente (cyberbullying), quando for praticado com o uso de comunicação via internet, sendo que neste último caso, o alcance e consequências da violência são ainda maiores (Silva, 2015).

Embora legalmente o conceito de bullying no Brasil seja novo, pois a Lei 13.185 entrou em vigor apenas no ano de 2016, doutrinariamente o conceito já tem sido explorado há bastante tempo. Segundo Silva e Costa (2016), o pesquisador Olwes iniciou pesquisas sobre violência escolar, identificando características peculiares do que veio a denominar bullying, na década de 70. Dentre os conceitos apesentados, destaca-se a peculiaridade do bullying ser realizado entre pares, de maneira repetitiva e intencional, sempre com uma relação desproporcional de poder entre os envolvidos, de modo que a violência gere transtornos como angustia, dor e consequências de todo tipo para vítimas e agressores (Silva, 2015; Silva \& Costa, 2016; Machado \& Piogozi, 2015).

Outra importante e indiscutível característica do bullying é a identificação dos envolvidos no fenômeno, apontando-se pelo menos 03 (três) figuras: a vítima, que recebe a violência e é, na maioria dos casos, mais frágil psicologicamente; o agressor, a figura do "valentão" que pratica os atos de violência e o expectador, aquele que assiste os atos de violência e pode intervir ou não na contenda (Silva, 2015). O estudo do bullying, em relação aos atores do fenômeno, vem sendo realizado por diferentes enfoques, englobando análises sob o ponto de vista das vítimas, dos autores ou mesmo sob a perspectiva dos espectadores (Souza \& Almeida, 2011). Para Rech, Halpern, Tedesco \& Santos (2013) outra importante perspectiva abordado acerca do tema são os efeitos de causa e consequência da violência.

Partindo-se da acepção da Teoria Social Cognitiva- TSC, que estuda o comportamento humano no contexto social, destaca-se a abordagem de atos de agressividade do indivíduo. Esta teoria é baseada no homem enquanto ser dinâmico, que recebe influência e influencia o meio social em que se vive identificado como ser agêntico (Bandura, 1986). Um dos principais conceitos utilizados dentro da TSC é o da Agência Humana, segundo o qual o indivíduo é munido de intencionalidade, por isso ele é capaz de provocar mudanças na sociedade, assim como sofrer transformações pelo meio da sociedade em que vive. A partir do conceito de Agência Humana, o indivíduo vai se desenvolvendo e cria um padrão moral social, fazendo uso do processo de ofertar e receber preceitos da sociedade. Para a Teoria Social Cognitiva, o homem, exposto ao convívio social, forma sua moralidade utilizando-se dos modelos a que é exposto e fazendo uso do que a teoria denomina autorregulação. Esse processo de formação da moralidade é identificado como Agência Moral (Bandura, 2005).

O indivíduo é considerado autorregulado utiliza mecanismos internos para controlar suas ações, pois tem a possibilidade de antecipar resultados e, dependendo das consequências visualizadas mentalmente, pode paralisar seus atos, caso os resultados previsíveis não coadunem com seus preceitos (Bandura, 2005). Por outro lado, o indivíduo pode controlar a 
prática de seus atos tendo em vista as prováveis sanções sociais, legais ou pessoais, situações em que visualiza os resultados de suas atitudes e decide se vai agir ou não (Bandura, 2005).

Nota-se, contudo, que nem sempre o indivíduo, no processo de criação da moralidade, vai agir considerando os modelos que seriam adequados para a sociedade em que ele está inserido, como ocorre quando o indivíduo age agressivamente contra terceiros, portando-se de maneira inadequada ao meio que prega preceitos morais e legais da não violência (Bandura, Azzi \& Tognetta, 2015). Para isso, segundo a Teoria Social Cognitiva, o indivíduo utiliza mecanismos que o desliga da função de sentir-se punido pelo ato inadequado, retirando a culpa por praticar ato contrário ao padrão moral existente (Bandura, Azzi \& Polydoro, 2008).

O Desengajamento Moral é utilizado pelo homem quando ele, no desenvolvimento de sua moralidade, mesmo tendo a definição do que é certo e errado, que são reguladores da conduta humana, se furta de agir corretamente e age de maneira desumana, fazendo uso dos mecanismos para abster-se da autocondenação e, desta maneira, sentir-se mais confortável diante de uma situação que pode gerar repulsa na sociedade (Bandura, Azzi \& Polydoro, 2008). Para Bandura (2002), o homem normalmente não se envolve em condutas desajustadas sem que antes tenha uma justificativa plausível para si, por isso, ele utiliza de diferentes justificativas para cometer atos de agressividade em seu ambiente. As justificativas são usadas em diferentes contextos, destacando-se o ambiente militar como lugar propício para uso desses mecanismos, que também pode ser identificado em outros lugares, como nas escolas, por ocorrência do bullying (Bandura. 2002; Azzi, Elias Junior \& Corrêa, 2017).

O Desengajamento Moral, enquanto dispositivo para justificar condutas reprováveis, elenca 08 (oito) mecanismos, quais sejam: Justificação moral; Comparação vantajosa; Linguagem eufemística; Minimização; Ignorância ou distorção das consequências; Desumanização; Atribuição de culpa; Deslocamento de responsabilidade e Difusão de responsabilidade (Bandura, 2002).

De acordo com Bandura (2002), entende-se que na realização de comportamentos violentos, o indivíduo pode acreditar que está agindo em razão de um bem social que pode gerar satisfação para toda coletividade e, neste caso, age em nome da Justificação ou Justiça Moral (Bandura, Azzi \& Tognetta, 2015). Na realidade do bullying, pode-se contextualizar em uma situação em que um estudante bate no "valentão" da turma para que ele não cometa mais atos de violência naquele ambiente.

O indivíduo, diante de seus discursos, pode utilizar uma linguagem mascarada para amenizar os efeitos do comportamento e, desta forma, sentir-se mais à vontade para praticar atos reprováveis, neste caso, a utilização da Linguagem Eufemística. Este mecanismo é um recurso que pode ser utilizado para se liberar da autosanção (Azzi, 2011). Azzi, Elias Junior e Corrêa (2017) citam o exemplo de uma pessoa que agride verbalmente a outra, mas alega que foi apenas uma brincadeira, ou um ato de diversão. Outra forma de retirar a autossanção para praticar atos de agressividade é fazendo uma comparação do ato repreensível a atitudes mais repugnantes, o que é chamado de Comparação Vantajosa. Tal mecanismo ocorre, por exemplo, quando um estudante alega que exclui um colega do círculo de amizade porque é melhor do que agredi-lo fisicamente, considerando que o ato de excluir é menos gravoso e pode gerar uma liberação da autocensura, levando em conta a agressão física (Bandura, Azzi \& Tognetta, 2015).

A pessoa pode ainda praticar o mecanismo de Minimização, Ignorância ou Distorção das consequências, caracterizada quando o sujeito praticante de atos desumanos não enxerga as consequências do seu ato ou minimiza os afeitos para não se sentir culpado. Pode-se contextualizar no caso de alunos que ofendem seus pares utilizando comunicação pela internet, pois quando não se está de frente com a vítima, é mais fácil não enxergar a sequela resultante da agressão (Azzi, Elias Junior \& Corrêa, 2017). O ato da Desumanização do indivíduo também é um mecanismo do desengajamento e ocorre em situações que 
o homem pratica atos ofensivos alegando que a vítima não possui característica de ser humano na concepção do agressor, a vítima é um ser indigno e por essa razão merece ser violentada (Bandura, Azzi \& Tognetta, 2015). A título de exemplificação, cita-se a situação em que um estudante é perseguido por ser considerado um "porco imundo", que não realiza higiene básica.

O Deslocamento da Responsabilidade é utilizado quando o indivíduo alega que cometeu o ato ofensivo porque recebeu ordem de terceiros, superiores a ele. A ideia central é de que quando alguém ordena que o indivíduo realize algum ato repugnante, este não se sinta pessoalmente responsável (Bandura, Azzi \& Tognetta, 2015). Pode-se visualizar essa situação em relação ao bullying quando o "valentão" da turma ordena que um colega persiga algum aluno e este realiza o ato, exonerandose do sentimento de culpa por estar apenas executando uma ordem. A Difusão da Responsabilidade é exercida quando o indivíduo justifica a realização de atos agressivos por ter recebido influência de outras pessoas. Conforme entendimento de Bandura (2002), as pessoas estão mais propensas a realizar atos ofensivos quando estão em grupo e aderem sua conduta individual para execução de um ato agressivo. Nota-se no caso em que um grupo de alunos decide realizar bullying em desfavor de um colega de turma, e individualmente comete-se o ato, sendo que tal conduta pode ser encarada como inocente aos olhos de quem pratica, por estar sofrendo influências ou encorajamento.

Por fim, o último mecanismo é o da Atribuição da Culpa, exercido quando o agente da violência se libera de culpa por acreditar que está agindo daquela maneira em função da vítima ter provocado a situação. Neste mecanismo, o indivíduo ofensor acredita que a agressividade é responsabilidade da própria vítima (Azzi, Elias Junior \& Corrêa, 2017). Em relação ao bullying, pode-se exemplificar com a situação em que uma garota é excluída dos grupos por não ter o padrão de beleza considerado adequado pelos colegas.

Para Bandura (1991), o enfraquecimento da moralidade está relacionado com o enfraquecimento de processos que compõem a autorregulação, que são: a auto-obeservação, o automonitoramento e a autorreatividade. Durante o exercício destes processos, o indivíduo observa mentalmente e prevê o alcance de suas condutas, evitando realizar atos ofensivos. Neste sentido, o processo de desengajar-se dos preceitos morais está intimamente ligado a realização dos atos de agressividade. O processo de desengajamento não ocorre de uma única vez, ao contrário, o indivíduo, desde criança, é exposto ao processo de educação e, ao longo de sua vida, constrói padrões, conforme os exemplos expostos e, também, se distancia, conforme enfraquece os preceitos da moralidade (Bandura, 2008). Portanto, é importante, desde cedo, fortalecer a moralidade dos indivíduos, fazendo com que seja um exercício contínuo, evitando-se o desengajar da moralidade e, consequentemente, a realização de atos de violência (Bandura, 2002). Sendo assim, este estudo objetiva: verificar se os estudantes com idade entre 11 (onze) e 18 (dezoito) tiveram envolvimento (praticaram, sofreram ou testemunharam) situações de violência, na modalidade bullying, dentro das escolas que frequentaram; e avaliar a existência de uma tendência dos estudantes justificarem seus atos de agressividade por meio dos mecanismos do desengajamento moral.

\section{Metodologia}

O enfoque da pesquisa é quantitativo, de cunho exploratório e descritivo, pois a partir dos conceitos estudados e da formulação de um problema, buscou-se identificar a variáveis por intermédio de técnicas estatísticas para caracterizar os fenômenos estudados, que por sua natureza são observáveis e quantificáveis (Günther, 2006; Lima, 2008; Teixeira, 2014).

\subsection{Lócus e amostra}

A amostra da pesquisa foi composta de 430 alunos, selecionados de duas escolas públicas, localizadas no centro da cidade de Belém - Pará, que atendem alunos de bairros diversos, incluindo periferias da capital. A escolha das escolas foi realizada por conveniência, considerando alguns critérios de inclusão, sendo: escolas em que já ocorreram situações de 
bullying com frequência; escolas que atendam alunos do ensino fundamental e médio e escolas que tenham disponibilidade para participar da pesquisa.

As informações sobre ocorrência de bullying nas escolas selecionadas foram obtidas na Secretaria de Educação do Estado do Pará, por meio do setor de ações educacionais complementares, que em tese, recebe informações dos atos de violência ocorridos dentro das escolas da Região Metropolitana de Belém e posteriormente confirmadas nas diretorias das escolas. Salienta-se, contudo, que não existe um sistema seguro que administre as ocorrências de violência dentro das escolas do Estado do Pará.

A seleção dos participantes, também, foi realizada por conveniência, considerando-se os seguintes critérios de inclusão: (1) alunos com idade entre 11 (onze) e 18 (dezoito) anos que cursam entre o $5^{\circ}$ ano do ensino fundamental e o último ano do ensino médio; (2) de ambos os sexos; (3) com a devida autorização dos responsáveis; (4) com disponibilidade para participar da pesquisa. Os 430 participantes foram recrutados das salas de aula que tinham estudantes com perfil do critério de inclusão.

\subsection{Instrumento e coleta de dados}

Utilizou-se Inventário de Desengajamento Moral (IDM) construído especificamente para esta pesquisa, fundamentado nos mecanismos do desengajamento moral estudados pelo pesquisador Bandura (2002). O instrumento possuí 3 (três) opções de respostas: sim, não e outro (que corresponde a "nenhuma das respostas anteriores"). Está composto de 33 (trinta e três) itens, englobando 8 (oito) dimensões, que corresponde aos 8 (oito) mecanismos do desengajamento moral, sendo que cada dimensão é composta por 4 (quatro) ou 5 (cinco) itens. A título de exemplo, coloca-se o item no 26 da escala: Você já conheceu alguém tão insuportável e desprezível que nem merecia ser chamado de ser humano? Esta questão se refere ao mecanismo da Desumanização.

Utilizou-se ainda, um questionário de caracterização e de questões ligadas ao bullying, que foi construído pelo LASIG - Laboratório de sistema de informação e Georreferenciamento da Universidade Federal do Pará - UFPA, e adaptado à realidade da presente pesquisa.

Para realização da coleta, primeiramente foi solicitada autorização, via ofício, às diretoras dos dois estabelecimentos de ensino. Além de, um Termo de Consentimento Livre e Esclarecido - TCLE, que solicitava a autorização dos participantes que iriam participar do estudo. Após os procedimentos preliminares, iniciou-se a coleta propriamente dita, que foi realizada em dois dias, sendo um dia para cada escola, nos turnos na manhã e tarde, em 15 (quinze) turmas englobando alunos do $5^{\circ}$ ano do ensino fundamental ao último ano do ensino médio, escolhidas aleatoriamente pela direção da escola.

Os instrumentos foram aplicados por pesquisadores, alunos de mestrado dos programas de pós-graduação da UFPA, nas áreas de Educação - PPGED - e Segurança Pública - PPGSP (mestrado), de maneira simultânea. O tempo médio de preenchimentos dos instrumentos foi de 25 (vinte e cinco) minutos.

\subsection{Análise de dados}

Os dados foram analisados por meio de estatística descritiva, com cálculo de porcentagem, uso de tabelas e gráficos para representação dos resultados. Para tanto se utilizou o software SPSS 24.

\subsection{Questões éticas}

Esta pesquisa faz parte de um projeto guarda-chuva que estuda categorias psicológicas no contexto escolar e foi submetido ao comitê de ética do Instituto de Ciência da Saúde da Universidade Federal do Pará, aprovado por meio do Parecer 
de número 2.912.010. Além disso, o estudo foi desenvolvido em conformidade com os preceitos éticos definidos na Resolução $\mathrm{N}^{\circ}$ 005/2017 PPGSP/UFPA, que assegura o respeito aos participantes do estudo, além da disponibilidade das escolas, levandose em consideração o melhor interesse dos alunos. Os sujeitos da pesquisa foram informados de maneira clara sobre o tema da pesquisa, por meio do Termo de Consentimento Livre e Esclarecido (TCLE), que foi encaminhado aos responsáveis dos estudantes.

\section{Resultados e Discussões}

\subsection{Dados de Caracterização}

Preliminarmente, foram analisados os dados de caracterização e fatores ligados à ocorrência do bullying dos alunos que compõem a amostra. Para esta fase aplicou-se estatística descritiva com medida separatriz - porcentagem. Objetivou-se traçar o perfil dos 430 (quatrocentos e trinta) estudantes entrevistados.

Em relação a variável sexo, dos 430 participantes da pesquisa, 216 eram do sexo masculino e 214 do sexo feminino, ficando aproximadamente 50\% para cada. Sobre a raça, 61\% da amostra (261 alunos) declararam-se pardos, 19\% brancos, $14 \%$ negros e quase 5\% declaram-se amarelos. Quanto à idade 124 alunos possuem entre 11 e 14 anos, somando aproximadamente $30 \%$ dos participantes, outros 286, estão com idade entre 15 e 18 anos, totalizando mais de $60 \%$ e uma última categoria que engloba.

A respeito de com quem residiam, $40 \%$ dos entrevistados afirmou morar com os pais (mãe e pai), $22 \%$ afirmou morar apenas com a mãe, e $11 \%$ afirmou morar com a mãe e com o padrasto, 24,5\% indicou morar só com o pai, os outros 24,6\% restantes informaram moradia com outros familiares, por exemplo, tios ou avós. Sobre a relação com os familiares, $93 \%$ indicou ter uma relação amigável com quem mora e outros $6 \%$ afirmou não ter uma boa relação em seu ambiente familiar. No Figura 1, é possível categorizar os grupos de amigos que os participantes da pesquisa se declararam.

Figura 1 - Percentual de estudantes das escolas do ensino público da região central de Belém-Pará, por grupo de amigos a que pertencem, 2018.

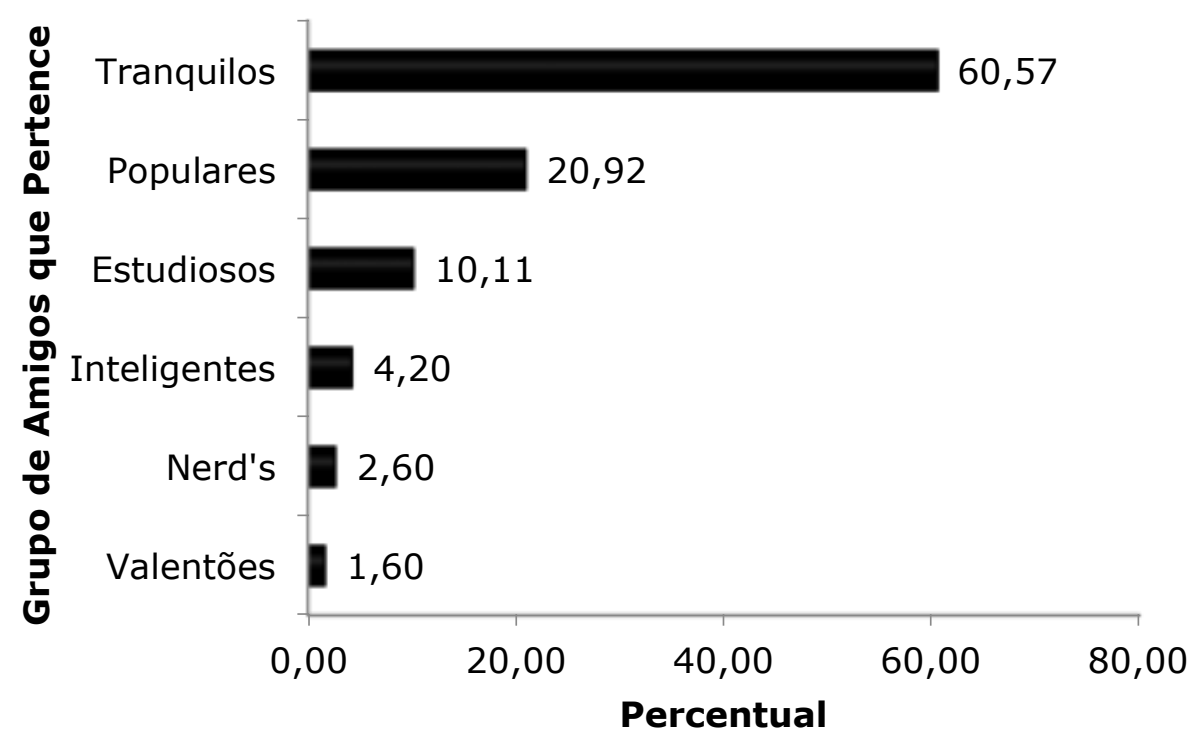

Fonte: Autoras (2019). 
Em relação aos grupos de amigos que fazem parte na escola, o Figura 01 demonstra que mais de $60 \%$ declarou pertencer a grupo dos tranquilos. Por outro lado, apenas $2 \%$ disseram compor o grupo dos "valentões", outros $10 \%$ se enquadraram dentre os estudiosos, $3 \%$ disseram ser parte do grupo dos nerd's e 21\% da amostra afirmou se encaixar no grupo dos populares. Há ainda os que informaram pertencer ao grupo dos inteligentes, $4 \%$.

Em relação ao comportamento na escola, é possível notar algumas categorias menos incidentes, sendo estas: bagunceiros $(3 \%)$, agitados $(8,5)$, tagarelas $(3,5)$, e outros $8,9 \%$ classificaram-se como tímidos. As categorias mais frequentes foram: brincalhões $(28,9 \%)$, extrovertidos $(20 \%), 15 \%$ comportados e $11 \%$ se consideraram calado. Destaca-se que apenas $1 \%$ declarou ser agressivo. Corroborando com este resultado, Silva et al. (2017), em estudo transversal para avaliar a existência e formas de manifestação do bullying, aplicaram questionário para 156 alunos do $6^{\circ}$ ao $9^{\circ}$ ano, no Estado de Alagoas. Os resultados mostraram que apenas 10,9\% dos alunos tinham sido suspensos e $64 \%$ dos alunos tinham participação disciplinar. Esse indicativo demonstra que o bullying não é praticado apenas por alunos que se consideram agressivos, ao contrário, qualquer aluno está propenso à prática dessa violência (Silva et al., 2017).

Ao serem questionados sobre como se sentiam dentro da escola, mais de $84 \%$ dos entrevistados afirmaram que sentiam-se feliz, $12 \%$ disseram que sentiam-se triste/infeliz e apenas 2,8\% declararam se sentir oprimido/pressionado. Quanto à percepção de pertencimento/exclusão 269 estudantes (63,3\%) afirmaram não que não se sentiam excluídos, ao contrário de 156 alunos (36,7\%) que disseram sentir-se excluídos dentro da escola. Silva et. al (2017), em estudo realizado sobre a temática, destacaram que 13,5\% da amostra referiu que já faltaram algumas vezes à escola por medo, demonstrando que a violência afasta os alunos da sala de aula, prejudicando o desempenho e envolvimento social.

\subsection{Análise das variáveis relativas ao bullying}

Sobre questões ligadas ao bullying, 93,4\% da amostra afirmou ter conhecimento sobre esse tipo de violência, ao revés de 6,6\% que declararam não saber do que se trata. Em relação ao envolvimento direto com atos de bullying, 37,6\% da amostra (160 estudantes), declararam já ter se envolvido em atos dessa natureza e 265 estudantes, englobando mais de $60 \%$ da amostra, respondeu nunca ter se envolvido em atos de bullying. Esse resultado foi mais elevado que o encontrado por Rech et. al (2013), quando estudaram a prevalência deste tipo de violência em uma amostra de 1.230 alunos que cursavam do $6^{\circ}$ ao $9^{\circ}$ ano, de uma escola na cidade Caxias do Sul-RS, pois indicaram que pouco mais de $19 \%$ da amostra tinha se envolvido em atos de bullying, englobando vítimas e agressores. Por outro lado, o Instituto Brasileiro de Geografia e Estatística - IBGE, ao realizar a Pesquisa de Saúde Escolar - PeNSE, em diversas cidades do Brasil, no ano de 2009, identificou que 24,5\% dos estudantes do estado do Pará, entrevistados, alegaram que já sofreram bullying no ambiente escolar (IBGE, 2009). Estes dados indicam uma prevalência acentuada deste tipo de violência no estado, sendo necessária construção e aplicação de políticas de conscientização e controle.

Sobre a percepção de segurança dentro da escola, em relação à proteção, quanto à agressão física, perseguições constantes de alunos com socos, chutes, tapas e agressões verbais, 53,6\% dos alunos declararam sentirem-se seguros, por outro lado, $46,4 \%$ dos participantes afirmaram exatamente o contrário, ou seja, não se sentiam seguros dentro da escola. Este é outro percentual elevado que necessita de atenção e tratamento adequado. Notou-se que a percepção de insegurança nas duas escolas envolvidas na pesquisa é alta.

Teixeira e Kassouf (2015) realizaram estudo para mensurar o impacto da violência no desenvolvimento de alunos do Estado de São Paulo, utilizando um modelo logit multinível. Os autores inferiram dentre os resultados, que a violência diminui em $0,54 \%$ a probabilidade dos alunos da terceira série do ensino médio apesentarem desempenho satisfatório em matemática. 
Os pesquisadores ressaltaram que a violência nas escolas afeta consideravelmente crianças e adolescentes que passam a apresentar um menor nível de aprendizagem e desempenho nas atividades escolares.

Em relação ao cruzamento das variáveis "percepção de exclusão" e "tipos de grupos de amigos", destacou-se dentre os resultados, que dos 11 (onze) alunos que se identificaram como "nerds", 8 (oito) deles declararam que sentiam-se excluído no ambiente escolar. Silva e Costa (2016) realizaram estudo nas escolas de ensino básico do estado Minas Gerais e analisaram dados empíricos de 5.300 alunos e 243 professores nos anos de 2012 e 2013, com objetivo de tentar compreender o bullying, considerando as características individuais do aluno e o contexto da escola. Em conclusão, os pesquisadores ressaltaram que o bullying não leva em consideração fatores isolado dos alunos, ou seja, as características individuais, não são geradoras de violência, deve-se atentar para as relações sociais desenvolvidas no ambiente escolar com um todo. Ressalta-se que dentro das categorias dos alunos que se incluíram nos grupos dos tranquilos, somando 257 estudantes da amostra, 157 deles (61\%) disse que não se sentia excluído e aqueles que se enquadraram como populares, 89 alunos da amostra, 66 deles (74\%) também indicaram não se sentir excluído. A partir desses dados, pode-se influir que os alunos que possuem facilidade de comunicação, pelas características individuais, apontaram que estão incluídos no ambiente escolar. Na Tabela 1, pode-se observar o cruzamento das variáveis relacionadas à como o aluno se sente no ambiente escolar e seu comportamento.

Tabela 1 - Cruzamento das variáveis de como o aluno se sentia no ambiente escolar e qual comportamento dele na escola.

\begin{tabular}{|c|c|c|c|c|c|}
\hline & & \multicolumn{3}{|c|}{ Como você se sente no ambiente escolar? } & \multirow{2}{*}{ Total } \\
\hline & & $\begin{array}{c}\text { oprimido/ } \\
\text { pressionado }\end{array}$ & triste/infeliz & feliz & \\
\hline \multirow{18}{*}{$\begin{array}{l}\text { Como você classifica } \\
\text { seu comportamento na } \\
\text { escola? }\end{array}$} & \multirow{2}{*}{ agressivo } & 0 & 2 & 2 & 4 \\
\hline & & $0,0 \%$ & $50,0 \%$ & $50,0 \%$ & $100,0 \%$ \\
\hline & \multirow{2}{*}{ bagunceiro } & 0 & 3 & 10 & 13 \\
\hline & & $0,0 \%$ & $23,1 \%$ & $76,9 \%$ & $100,0 \%$ \\
\hline & \multirow{2}{*}{ calado } & 3 & 12 & 32 & 47 \\
\hline & & $6,4 \%$ & $25,5 \%$ & $68,1 \%$ & $100,0 \%$ \\
\hline & \multirow{2}{*}{ tímido } & 0 & 6 & 32 & 38 \\
\hline & & $0,0 \%$ & $15,8 \%$ & $84,2 \%$ & $100,0 \%$ \\
\hline & \multirow{2}{*}{ brincalhão } & 4 & 7 & 112 & 123 \\
\hline & & $3,3 \%$ & $5,7 \%$ & $91,1 \%$ & $100,0 \%$ \\
\hline & \multirow{2}{*}{ agitado } & 0 & 5 & 31 & 36 \\
\hline & & $0,0 \%$ & $13,9 \%$ & $86,1 \%$ & $100,0 \%$ \\
\hline & \multirow{2}{*}{ tagarela } & 1 & 1 & 13 & 15 \\
\hline & & $6,7 \%$ & $6,7 \%$ & $86,7 \%$ & $100,0 \%$ \\
\hline & \multirow{2}{*}{ comportado } & 1 & 9 & 53 & 63 \\
\hline & & $1,6 \%$ & $14,3 \%$ & $84,1 \%$ & $100,0 \%$ \\
\hline & \multirow{2}{*}{ extrovertido } & 3 & 6 & 76 & 85 \\
\hline & & $3,5 \%$ & $7,1 \%$ & $89,4 \%$ & $100,0 \%$ \\
\hline \multirow{2}{*}{\multicolumn{2}{|c|}{ Total }} & 12 & 51 & 361 & 424 \\
\hline & & $2,8 \%$ & $12,0 \%$ & $85,1 \%$ & $100,0 \%$ \\
\hline
\end{tabular}

Fonte: Autoras (2019).

No cruzamento da Tabela 01, destaca-se que 47 alunos da amostra se enquadraram na categoria dos calados, dos quais, $12(25,5 \%)$ disseram que se sentiam infeliz e 3 alunos $(6,4 \%)$ indicaram que se sentiam oprimidos dentro da escola. Apenas 4 alunos da amostra se identificaram como agressivos, sendo que metade deles (50\%) referiu que estavam infelizes na escola. Em estudo, Sampaio et. al (2015) investigaram as emoções de alunos envolvidos em atos de bullying, aplicando um questionário para 232 alunos do sexto ao nono ano de escola pública, inferiu-se que 25,9\% dos agressores de bullying sentiam- 
se tristes. Na Tabela 2, observa-se o cruzamento das variáveis de como o aluno se sente no ambiente escolar e suas características individuais.

Tabela 2 - Cruzamento das variáveis de como o aluno se sente no ambiente escolar (seguros ou inseguros) com suas características individuais (tímidos, calado, agressivo, etc.).

\begin{tabular}{|c|c|c|c|c|}
\hline & & \multicolumn{2}{|c|}{$\begin{array}{c}\text { Percepção de segurança quanto a } \\
\text { agressões físicas (perseguições } \\
\text { constantes de alunos com socos, chutes, } \\
\text { tapas entre outros) e agressões verbais }\end{array}$} & \multirow[t]{2}{*}{ Total } \\
\hline & & seguro & inseguro & \\
\hline \multirow{18}{*}{$\begin{array}{l}\text { Como você classifica } \\
\text { seu comportamento na } \\
\text { escola? }\end{array}$} & \multirow{2}{*}{ agressivo } & 3 & 1 & 4 \\
\hline & & $75,0 \%$ & $25,0 \%$ & $100,0 \%$ \\
\hline & \multirow{2}{*}{ bagunceiro } & 11 & 2 & 13 \\
\hline & & $84,6 \%$ & $15,4 \%$ & $100,0 \%$ \\
\hline & \multirow{2}{*}{ calado } & 39 & 8 & 47 \\
\hline & & $83,0 \%$ & $17,0 \%$ & $100,0 \%$ \\
\hline & \multirow{2}{*}{ tímido } & 28 & 10 & 38 \\
\hline & & $73,7 \%$ & $26,3 \%$ & $100,0 \%$ \\
\hline & \multirow{2}{*}{ brincalhão } & 96 & 27 & 123 \\
\hline & & $78,0 \%$ & $22,0 \%$ & $100,0 \%$ \\
\hline & \multirow{2}{*}{ agitado } & 28 & 8 & 36 \\
\hline & & $77,8 \%$ & $22,2 \%$ & $100,0 \%$ \\
\hline & \multirow{2}{*}{ tagarela } & 13 & 2 & 15 \\
\hline & & $86,7 \%$ & $13,3 \%$ & $100,0 \%$ \\
\hline & \multirow{2}{*}{ comportado } & 50 & 14 & 64 \\
\hline & & $78,1 \%$ & $21,9 \%$ & $100,0 \%$ \\
\hline & \multirow{2}{*}{ extrovertido } & 68 & 17 & 85 \\
\hline & & $80,0 \%$ & $20,0 \%$ & $100,0 \%$ \\
\hline \multirow{2}{*}{\multicolumn{2}{|c|}{ Total }} & 336 & 89 & 425 \\
\hline & & $79,1 \%$ & $20,9 \%$ & $100,0 \%$ \\
\hline
\end{tabular}

Fonte: Autoras (2019).

Analisando o cruzamento acima, observou-se que os resultados indicaram que dos 4 (quatro) alunos da amostra que se caracterizaram como agressivos, 1 (25\%) deles afirmou se sentir inseguro no ambiente escolar. Na categoria dos que se consideram tímidos, soma-se 38 estudantes da amostra, 10 (26,3\%) deles, também referiram se sentir inseguros dentro da escola. Considerando-se todas as categorias, ressalta-se que 89 (20,9\%) alunos da amostra indicaram que se sentiam inseguros dentro da escola, conforme a Tabela 2 .

No cruzamento entre as informações sobre com quem os alunos moravam (com os pais, só com a mãe, só com o pai, com o pai e a madrasta, com a mãe e o padrasto, com os tios, com os avós e outros) com informações sobre qual a relação que eles tinham com quem estavam morando, destaca-se que 170 estudantes da amostra afirmaram que moravam com os pais, dos quais 156 (90\%) informaram que tinham relação amigável. De forma geral, dos 430 alunos participantes, considerando a amostra total, apenas 26 alunos (6\%) relataram que tinham relação agressiva com quem moravam. Sobre a participação da família no contexto da prática de bullying, Borsa, Petrucci e Koller (2014), ressaltam a importância do cruzamento entre as variáveis familiares e a prática de bullying, destacando a importância da realização de trabalhos empíricos nacionais que busquem avaliar a relação de estudantes com seus familiares para interagir escola, família e alunos, no sentido de evitar ocorrência no ambiente escolar. 
Destaca-se, também, que o percentual dos estudantes que se sentem seguros dentro da escola foi mais alto dentro da categoria dos alunos que nunca estiveram envolvidos em atos de bullying, pois dos 265 alunos que declararam que nunca se envolveram em atos dessa magnitude, 225 (84,9\%) declararam que se sentiam seguros no ambiente escolar. Em estudo, Santos, Perkoski e Kienen (2015), buscaram analisar a percepção de 6 (seis) professores e 83 (oitenta e três) alunos do ensino fundamental sobre consequências, causas e medidas preventivas do bullying, ocorrido dentro de uma escola pública em Florianópolis. $\mathrm{O}$ autores utilizaram como instrumento um roteiro entrevista semi-estruturada para os professores e um questionário aplicado aos alunos, exploraram os dados por meio de estatística descritiva e análise de conteúdo. Dentre os resultados, os pesquisadores destacaram que os alunos que sofriam bullying, passavam a sentir muito medo dentro das escolas, tanto que durante os intervalos de recreio, ficavam mais perto da sala dos professores e da sala da direção e dentro da sala de aula, evitavam ou não gostavam de trabalho em grupo. Deste modo, avançou-se para o cruzamento das variáveis de subjetividade, bullying e desengajamento moral, construto abordado.

\subsection{Cruzamento de variáveis relativas às características pessoais, bullying e ao desengajamento moral}

Por fim, foram analisados os dados relacionados ao perfil, o envolvimento dos alunos na prática de bullying e os questionamentos relacionados aos mecanismos do desengajamento moral A Tabela 3 mostra o cruzamento de alguns dos mecanismos de desengajamento moral, relacionando-os com o envolvimento em atos de bullying.

Tabela 3 - Cruzamento de variáveis relativas ao envolvimento com bullying e os mecanismos do Desengajamento moral.

Você já esteve envolvido em atos de Bullying na sua escola?

\begin{tabular}{|c|c|c|c|c|c|c|c|c|}
\hline Item & Mecanismo & & Masc & Fem & Total & Sim & Não & $\begin{array}{c}\text { Total } \\
*\end{array}$ \\
\hline \multirow{2}{*}{$\begin{array}{l}\text { É comum excluir um } \\
\text { colega que acabou de } \\
\text { chegar na escola para } \\
\text { manter amigos mais } \\
\text { antigos? }\end{array}$} & \multirow{2}{*}{$\begin{array}{l}\text { Justificativa } \\
\text { Moral }\end{array}$} & Sim & $\begin{array}{c}73 \\
17,2 \%\end{array}$ & $\begin{array}{c}90 \\
21,2 \%\end{array}$ & $\begin{array}{c}163 \\
38,4 \%\end{array}$ & $\begin{array}{c}69 \\
16,2 \%\end{array}$ & $\begin{array}{c}94 \\
22,1 \%\end{array}$ & $\begin{array}{c}163 \\
38,4 \%\end{array}$ \\
\hline & & Não & $\begin{array}{c}135 \\
31,8 \%\end{array}$ & $\begin{array}{l}119 \\
28 \%\end{array}$ & $\begin{array}{c}254 \\
59,8 \%\end{array}$ & $\begin{array}{c}86 \\
20,2 \%\end{array}$ & $\begin{array}{c}168 \\
39,5 \%\end{array}$ & $\begin{array}{c}254 \\
59,8 \%\end{array}$ \\
\hline \multirow{2}{*}{$\begin{array}{l}\text { Você acha que esconder } \\
\text { os objetos de um colega } \\
\text { descuidado é apenas } \\
\text { uma brincadeira? }\end{array}$} & \multirow{2}{*}{$\begin{array}{l}\text { Linguagem } \\
\text { eufemística }\end{array}$} & Sim & $\begin{array}{l}40 \\
9,4 \%\end{array}$ & $\begin{array}{c}32 \\
7,5 \% \\
\end{array}$ & $\begin{array}{c}72 \\
16,9 \% \\
\end{array}$ & $\begin{array}{c}29 \\
6,8 \% \\
\end{array}$ & $\begin{array}{c}43 \\
10,1 \% \\
\end{array}$ & $\begin{array}{c}72 \\
16,9 \% \\
\end{array}$ \\
\hline & & Não & $\begin{array}{c}159 \\
37,4 \%\end{array}$ & $\begin{array}{c}174 \\
40,9 \%\end{array}$ & $\begin{array}{c}333 \\
78,4 \%\end{array}$ & $\begin{array}{c}123 \\
28,9 \%\end{array}$ & $\begin{array}{c}210 \\
49,4 \%\end{array}$ & $\begin{array}{c}333 \\
78,4 \%\end{array}$ \\
\hline \multirow{2}{*}{$\begin{array}{l}\text { Você já usou a frase: } \\
\text { "achado não é roubado } \\
\text { quem perdeu é } \\
\text { relaxado", tendo em } \\
\text { vista que isto não é tão } \\
\text { grave, pois algumas } \\
\text { pessoas roubam as } \\
\text { outras? }\end{array}$} & \multirow[b]{2}{*}{$\begin{array}{l}\text { Comparação } \\
\text { vantajosa }\end{array}$} & Sim & $\begin{array}{c}81 \\
19,1 \% \\
\end{array}$ & $\begin{array}{c}80 \\
18,8 \% \\
\end{array}$ & $\begin{array}{c}161 \\
37,9 \% \\
\end{array}$ & $\begin{array}{c}60 \\
14,1 \% \\
\end{array}$ & $\begin{array}{c}101 \\
23,8 \%\end{array}$ & $\begin{array}{c}161 \\
37,9 \% \\
\end{array}$ \\
\hline & & Não & $\begin{array}{c}117 \\
27,5 \%\end{array}$ & $\begin{array}{c}109 \\
25,6 \%\end{array}$ & $\begin{array}{c}226 \\
53,2 \%\end{array}$ & $\begin{array}{c}86 \\
20,2 \%\end{array}$ & $\begin{array}{c}140 \\
32,9 \%\end{array}$ & $\begin{array}{c}22,6 \\
53,2 \%\end{array}$ \\
\hline \multirow{2}{*}{$\begin{array}{l}\text { Não é justo culpar um } \\
\text { aluno que teve apenas } \\
\text { uma pequena } \\
\text { participação no dano } \\
\text { causado por um grupo. }\end{array}$} & \multirow{2}{*}{$\begin{array}{l}\text { Difusão de } \\
\text { responsabilidade }\end{array}$} & Sim & $\begin{array}{c}81 \\
19,1 \% \\
\end{array}$ & $\begin{array}{c}74 \\
17,4 \% \\
\end{array}$ & $\begin{array}{c}155 \\
36,5 \% \\
\end{array}$ & $\begin{array}{c}62 \\
14,6 \% \\
\end{array}$ & $\begin{array}{c}93 \\
21,9 \% \\
\end{array}$ & $\begin{array}{c}155 \\
36,5 \%\end{array}$ \\
\hline & & Não & $\begin{array}{c}117 \\
27,5 \%\end{array}$ & $\begin{array}{c}127 \\
29,9 \%\end{array}$ & $\begin{array}{c}244 \\
57,4 \%\end{array}$ & $\begin{array}{c}94 \\
22,1 \%\end{array}$ & $\begin{array}{c}150 \\
35,3 \%\end{array}$ & $\begin{array}{c}244 \\
57,4 \%\end{array}$ \\
\hline $\begin{array}{l}\text { O aluno não deve ser } \\
\text { responsabilizado por um }\end{array}$ & $\begin{array}{l}\text { Deslocamento de } \\
\text { responsabilidade }\end{array}$ & Sim & $\begin{array}{c}63 \\
14,8 \%\end{array}$ & $\begin{array}{c}56 \\
13,2 \%\end{array}$ & $\begin{array}{l}119 \\
28 \%\end{array}$ & $\begin{array}{c}51 \\
12 \%\end{array}$ & $\begin{array}{c}68 \\
16 \%\end{array}$ & $\begin{array}{l}119 \\
28 \%\end{array}$ \\
\hline
\end{tabular}




\begin{tabular}{|c|c|c|c|c|c|c|c|c|}
\hline $\begin{array}{l}\text { ato que foi obrigado a } \\
\text { fazer? }\end{array}$ & & Não & $\begin{array}{c}132 \\
31,1 \%\end{array}$ & $\begin{array}{c}144 \\
33,9 \%\end{array}$ & $\begin{array}{c}276 \\
64,9 \%\end{array}$ & $\begin{array}{c}97 \\
22,8 \%\end{array}$ & $\begin{array}{c}179 \\
42,1 \%\end{array}$ & $\begin{array}{c}276 \\
64,9 \%\end{array}$ \\
\hline \multirow{2}{*}{$\begin{array}{l}\text { Excluir colegas de seus } \\
\text { grupos machuca os } \\
\text { excluídos? }\end{array}$} & \multirow{2}{*}{$\begin{array}{l}\text { Distorsão das } \\
\text { consequências }\end{array}$} & Sim & $\begin{array}{c}164 \\
38,6 \%\end{array}$ & $\begin{array}{l}187 \\
44 \%\end{array}$ & $\begin{array}{c}351 \\
82,6 \%\end{array}$ & $\begin{array}{c}135 \\
38,5 \%\end{array}$ & $\begin{array}{c}216 \\
50,8 \%\end{array}$ & $\begin{array}{c}351 \\
82,6 \%\end{array}$ \\
\hline & & Não & $\begin{array}{c}33 \\
7,8 \%\end{array}$ & $\begin{array}{c}19 \\
4,5 \%\end{array}$ & $\begin{array}{c}52 \\
12,2 \%\end{array}$ & $\begin{array}{c}19 \\
4,5 \%\end{array}$ & $\begin{array}{c}33 \\
7,8 \%\end{array}$ & $\begin{array}{c}52 \\
12,2 \%\end{array}$ \\
\hline \multirow{2}{*}{$\begin{array}{l}\text { Você já conheceu } \\
\text { alguém tão insuportável } \\
\text { e desprezível que nem } \\
\text { merecia ser chamado de } \\
\text { humano? }\end{array}$} & \multirow{2}{*}{ Desumanização } & Sim & $\begin{array}{c}114 \\
26,8 \%\end{array}$ & $\begin{array}{c}133 \\
31,3 \%\end{array}$ & $\begin{array}{c}247 \\
58,1 \%\end{array}$ & $\begin{array}{c}94 \\
22,1 \%\end{array}$ & $\begin{array}{l}153 \\
36 \%\end{array}$ & $\begin{array}{c}247 \\
58,1 \%\end{array}$ \\
\hline & & Não & $\begin{array}{c}92 \\
21,6 \%\end{array}$ & $\begin{array}{c}68 \\
16 \%\end{array}$ & $\begin{array}{c}160 \\
37,6 \%\end{array}$ & $\begin{array}{c}59 \\
13,9 \%\end{array}$ & $\begin{array}{c}101 \\
23,8 \%\end{array}$ & $\begin{array}{c}160 \\
37,6 \%\end{array}$ \\
\hline
\end{tabular}

* referente a amostra total - 430. Fonte: Autoras (2019).

Para averiguar o grau de desengajamento moral relacionado ao mecanismo da justificação moral, utilizou-se o seguinte questionamento aos estudantes: "É comum excluir um colega que acabou de chegar na escola para manter amigos mais antigos?". Em resposta, conforme dados da Tabela 3, 163 (cento e sessenta e três) alunos, equivalente a 38\% (trinta e oito por cento) da amostra total, responderam que SIM, indicando comportamento justificador de atos agressivos. Note-se ainda que dos citados 163 (cento e sessenta e três) estudantes com tendências a justificar seus atos por este mecanismo, 69 (sessenta e nove) deles responderam que já estiveram envolvidos em atos de bullying. Este resultado se coaduna com o estudo de Parnari e Wood (2009), os quais realizaram pesquisa com 339 (trezentos e trinta e nove) estudantes do ensino médio, no Reino Unido. Os quais analisaram a relação do desengajamento moral com bullying e cyberbullying, inferindo que os mecanimos mais utilizados por estudantes envolvidos em agressões foram a justificação moral e a linguagem eufemistica.

O mecanismo da Linguagem Eufemística foi analisado, dentre outras perguntas, pela seguinte: "Você acha que esconder objetos de um colega descuidado é apenas uma brincadeira?". Neste item, mais de 16,9\% das respostas dos alunos foram SIM, indicando justificação de atos de violência. Em análise do mecanismo da Comparação vantajosa, se utilizou a pergunta: "Você já usou a frase 'achado não é roubado, quem perdeu é relaxado', tendo em vista que isto não é tão grave, pois algumas pessoas roubam as outras?". Neste quesito, de acordo com a Tabela 3, quase 37,9\% da amostra (161 alunos) concordaram com a frase, apontando comportamento tendencioso a justificar suas condutas. Destes 161 alunos, pelo menos 14\%, ou seja, 60 estudantes, afirmaram que já se envolveram em atos de bullying. Semelhante ao estudo realizado por Grundher et al. (2017), na Alemanha, com 925 estudantes, com idades entre 11 (onze) e 17 (dezessete) anos. O quais utilizaram um questionário para analisar o envolvimento dos alunos com bullying e escala de Bandura para mensurar o desengajamento moral, tendo como resultado relevante, a significativa relação entre atitudes pró-bullying dos estudantes com o desengajamento moral.

No mecanismo da Difusão da responsabilidade dos estudantes foi auferido com a seguinte afirmação: "Não é justo culpar um aluno que teve apenas uma participação no dano causado por um grupo". Em conformidade com os dados da Tabela 3,155 alunos responderam que concordavam com a sentença, demonstrando comportamento inclinado a justificar atos de violência. Ressalta-se que destes 155 estudantes, pelo menos 62 deles responderam que já haviam se envolvido em situações de bullying. Neste mesmo sentido Çapan e Bakioglu (2016), objetivaram validar a escala do desengajamento moral coletivo e a relação com bullying, tendo-a desenvolvido com 339 alunos (10 a 17 anos), em 02 etapas. Os autores inferiram que quanto maior o nível de desengajamento moral dos alunos, maior o nível de envolvimento em situações de bullying.

O mecanismo de Deslocamento da Responsabilidade, analisado pela indagação "O aluno não deve ser responsabilizado por um ato que foi obrigado a fazer?", a prevalência foi de quase $65 \%$ ) de concorcondância, indicando forte tendência justificadora dos estudantes neste quesito. Por outro lado, no questionamento "Excluir colegas de seus grupos 
machuca os excluídos?", que analisa o mecanismo da Distorsão das consequências, $12 \%$ das respostas obtidas foram de cunho negativo, indicando uma razoável tendência justificadora dos alunos quanto a este tópico e falta de empatia.

$\mathrm{Na}$ percepção dos alunos, quantos ao seu comportamento, frente ao mecanismo da Desumanização, foi indicada a seguinte pergunta: "Você já conheceu alguém tão insurpotável e desprezível que nem merecia ser chamado de humano?". De acordo com a Tabela 3, 58\% da amostra (247 alunos) respondeu positivamente, indicando comportamento justificador de condutas agressiva. Desses, 247 estudantes, pelo menos 94 deles também responderam que já havia se envolvido em contendas relacionadas ao bullying. Gini, Pazoli, e Vieno (2015)investigaram os mecanismos com atitudes pró-bullying de 663 estudantes do $4^{\circ}$ e $5^{\circ}$ ano de 38 escolas públicas da Itália. Dentre os resultados, destaca-se a relação positiva entre o bullying e o desengajamento moral, principalmente no mecanismo da desumanização e minimização do resultado.

Percebe-se, diante das discussões, que existe uma tendência considerável dos alunos justificarem seus atos de agressividade, ou seja, os estudantes, ao comenterem atos moralmente reprováveis, retiram de alguma maneira, a censura daquela atitude. Esse processo, sengundo Bandura, Barbranelli, Carprara \& Pastorelli (1996), influencia a prática de outros atos reprováveis. Diante disso, se faz necessário estimular o engajamento moral do indivíduo desengajado, pois havendo a autossanção, característica de quem age de acordo com os padrões morais da sociedade, o agente estará menos disposto a praticar atos de violência.

\section{Considerações Finais}

A presente pesquisa teve como objetivo principal, verificar se estudantes com idade entre 11 e 18 anos tiveram envolvimento (praticaram, sofreram ou testemunharam) situações de violência na modalidade bullying dentro das escolas que frequentaram, além de caracterizar a amostra composta de 430 (quatrocentos e trinta) estudantes e avaliar a existência de uma tendência dos estudantes justificarem seus atos de agressividade por meio dos mecanismos do desengajamento moral

Enfatiza-se que foi visualizado o envolvimento dos estudantes em bullying, com a prevalência de mais de $30 \%$ da amostra, percentual bem considerável, se tratando de ambiente escolar. Constatou-se, também, que existe uma tendência dos estudantes em justificar seus atos agressivos por meio de "desculpas", as quais, dentro da pesquisa, se enquadraram com os mecanismos do desengajamento moral, pois em todas as categorias apresentadas no inventário existiram respostas indicando essa tendência por parte dos participantes. Dentre os resultados obtidos na pesquisa, destaca-se que $40 \%$ (quarenta por cento) dos entrevistados afirmaram que estavam residindo com os pais (mãe e pai). Nota-se, diante desse resultado, que a família tradicional, composta de pai, mãe e filhos, foi encontrada em menos da metade dos entrevistados, o que pode sugerir uma falta de direcionamento aos jovens no que se refere aos preceitos morais da sociedade.

Outro resultado importante deste estudo foi em relação aos grupos existentes na escola, pois mais de $60 \%$ da amostra declarou pertencer ao grupo dos tranquilos e apenas $2 \%$ afirmou participar do grupo dos valentões, inferindo-se que as contendas envolvendo bullying existem em outros grupos e não apenas no grupo dos mais valentes. Em relação à justificação dos atos agressivos, enfatiza-se o resultado encontrado em uma das perguntas, "O aluno não deve ser responsabilizado por um ato que foi obrigado a fazer? para auferir o mecanismo do deslocamento da responsabilidade, que obteve a prevalência de quase $65 \%$ de concorcondância, indicando forte tendência justificadora dos estudantes neste quesito.

Entretanto, no decorrer da pesquisa, não foram identificadas investigações acerca do desengajamento moral e a prática de bullying entre estudantes. Identificando, também, a ausência de estudos abordando a prevenção de violência sob viés do comportamento humano baseado no desengajamento moral. Deste modo, como limitação de estudo aponta-se a ausência de testes estatística para verificar a relação entre o desengajamento moral e a violência escolar, sendo esta uma indicação para futuras pesquisas neste contexto. 
Diante do exposto, nota-se, como sugestão de estudos vindouros, a necessidade de intervenção dentro das escolas, envolvendo os estudantes, para que reconheçam a necessidade de extinguir o bullying do ambiente escolar. Neste caso específico, a intervenção poderá ocorrer no sentido de engajar os alunos aos preceitos morais sociais, buscando conscientizálos da necessidade de respeitar o próximo, de enxergar as diferenças e de buscar a valorização da amizade para crescimento pessoal e de toda coletividade envolvida naquele mesmo espaço.

\section{Referências}

Azzi, R. G., Elias Junior, J. L., \& Corrêa, W. G. (2017). Agência moral na visão da Teoria Social Cognitiva. Letral.

Azzi, Roberta G. (2011). Desengajamento moral na perspectiva da Teoria Social Cognitiva. Psicologia: Ciência e Profissão, Brasília, DF, 31(2) 208-219.

Bandura. A. (1986). Social foundations of thou and action: a social cognitive theory. Englewood Cliffs, N.J.: Prentice-Hall.

Bandura. A. (1991). Social cognitive theory of self-regulation. Organizational behavior and human decision processes, 50(2), $248-287$.

Bandura. A. (2002). Selective Moral Disengagement in the Exercise of Moral Agency. Journal of Moral Education, 31(2) 101-119.

Bandura. A. (2005). The evolution of social cognitive theory. In: Smith, K. G., Hitt, M. A. (Ed.) Great minds in management. Oxford: Oxford University Press, 9-35.

Bandura, A., Azzi, R. G \& Tognetta, L. A. (Org.). (2015). Desengajamento moral: teoria e pesquisa a partir da Teoria Social Cognitiva. Mercado de Letras.

Bandura, A., Azzi. R. G., Polydoro, S. (2008). Teoria Social Cognitiva: conceitos básicos. Artmed.

Bandura, A., Barbranelli, C, Carprara, G. C. \& Pastorelli. C. (1996). Mechanisms of Moral Disengagement in the Exercise of Moral Agency. Journal of Personality and Social Psychology, 71(2), 364-374.

Borsa, J., Petrucci, G. \& Koller, S. (2015). A Participação dos pais nas pesquisas sobre o bullying escolar. Revista Quadrimestral da Associação Brasileira de Psicologia Escolar e Educacional, SP, 19(1), 41-48, jan./abr.

Brasil. (2015). Lei No 13.185, de 6 de novembro de 2015. Institui o Programa de Combate à Intimidação Sistemática (Bullying). Brasília, DF.

Çapan, B. \& Bakioğlu, F. (2016). Adaptation of collective moral disengagement scale into Turkish culture for adolescents. Universal Journal of Educational Research, Turkey, 4(6), 1452- 1457.

Gini, G., Pozzoli, T., Bussey, K. (2015). The role of individual and collective moral disengagement in peer aggression and bystanding: a multilevel analysis. Journal of Abnormal Child Psychology, New York, 3, 441-452.

Grundherr, M. et al. (2017). School bullying and moral reasoning competence. Social Development, 26(2), $278-294$.

Gunther, H. (2006). Pesquisa Qualitativa Versus Perquisa Quantitativa. Esta É a questão? Psicologia: Teoria e Pesquisa, 22(2), 201-210.

IBGE. Instituto Brasileiro de Geografia e Estatística. (2009). Pesquisa Nacional de Saúde do Escolar: Rio de Janeiro.

Lima, M. C. Monografia. (2a ed.), Saraiva, 2008.

Machado, A. \& Pigozi, P. (2015). Bullying na adolescência: visão panorâmica no Brasil. Ciência e Saúde Coletiva. 20(11).

Matos, F. et al. Prevenção da violência através da resiliência dos alunos. Psicologia, Saúde \& Doenças, Lisboa, 16(1), 35-43, mar. 2015.

Olweus, D. (1995). Peer abuse or bullying at school: Basic facts and a school-based intervention programme. Prospects, 25, 133 -39.

Parnari, C. \& Wood, J. (2009). Peer and cyber aggression in secondary school students: the role of moral disengagement, hostile attribution bias, and ouctcome expectancies. Aggressive Behavior, 36, 81-94.

Rech, R. R., Halpern, R., Tedesco, A., \& Santos, D. F. (2013). Prevalence and characteristics of victims and perpetrators of bullying. Jornal de Pediatria, 89(2), 164-170.

Sampaio, M. C. S. et al. (2015). Prevalência de Bullying e Emoções de Estudantes Envolvidos. Texto, Contexto, Enfermagem, Florianópolis, 24(2), 344-52.

Santos, M., Perkoski, I. \& Kienen, N. (2015). Bullying: Atitudes, Consequências e Medidas Preventivas na Percepção de Professores e alunos do Ensino Fundamental. Trends e Psychology/ Temas em Psicologia, 23(4), 1017 - 1033.

Silva, Ana Beatriz Barbosa. Bullying: mentes perigosas nas escolas. (2a ed.), Globo, 2015.

Silva, C. S.\& Costa, B. L. D. (2016). Opressão nas escolas: o bullying entre estudantes do ensino básico. Cadernos de Pesquisa 46(161), 87-104.

Silva, D., Tavares, E., Silva, E., Duarte, J., Cabral, L. \& Martins, C. (2017). Vítimas e Agressores - Manisfestações de Bullying em alunos do $6^{\circ}$ ao $9^{\circ}$ ano de escolaridade. Revista Portuguesa de Enfermagem de Saúde Mental. 5, 57-62, agosto, 2017. 
Research, Society and Development, v. 10, n. 1, e44210111699, 2021

(CC BY 4.0) | ISSN 2525-3409 | DOI: http://dx.doi.org/10.33448/rsd-v10i1.11699

Souza, C. P. \& Almeida, L. C. P. (2011). Bullying em ambiente escolar. Enciclopédia Biosfera, Goiânia, 7(12), 179-190.

Teixeira, E. C. \& Kassouf, A. L. (2015). Impacto da Violência nas Escolas Paulistas sobre o Desempenho Acadêmico dos Alunos, 19(2), 221-240.

Teixeira, E. (2014). As Três Metodologias: acadêmica da ciência e da pesquisa. (8a ed.), Vozes. 